\title{
Evolutionary Game Simulation on Government Incentive Strategies of Prefabricated Construction: A System Dynamics Approach
}

\author{
Baoquan Cheng $\mathbb{D D}^{1}{ }^{1}$ Yuhu Wei, ${ }^{2}$ Wei Zhang, ${ }^{2}$ Xintao Zhou, ${ }^{2}$ Huihua Chen ${ }^{D},{ }^{1}$ \\ Lipeng Huang, ${ }^{3}$ Jianling Huang, ${ }^{1}$ and Xiaofang Kang ${ }^{2}$ \\ ${ }^{1}$ Department of Engineering Management, School of Civil Engineering, Central South University, Changsha, \\ Hunan 410075, China \\ ${ }^{2}$ School of Civil Engineering, Anhui Jianzhu University, Hefei, Anhui 230601, China \\ ${ }^{3}$ School of Foreign Language, Anhui Jianzhu University, Hefei, Anhui 230601, China
}

Correspondence should be addressed to Huihua Chen; chh24770@163.com

Received 31 August 2020; Revised 9 September 2020; Accepted 20 September 2020; Published 6 October 2020

Academic Editor: M. Irfan Uddin

Copyright (c) 2020 Baoquan Cheng et al. This is an open access article distributed under the Creative Commons Attribution License, which permits unrestricted use, distribution, and reproduction in any medium, provided the original work is properly cited.

\begin{abstract}
Prefabricated construction is a state-of-the-art construction technology of both socio-economic and environmental benefits, but sometimes, it is not welcome due to its high cost. Governments play an important role in deeply promoting prefabricated construction, but its effects are not clear. This paper developed a system dynamics model for investigating and simulating the impacts of government incentive strategies on prefabricated construction by considering the evolutionary game process between the government and contractors. Data of Shanghai, China, is collected for demonstration and validation of the developed simulation model. Results show that (1) the evolutionary stable strategy does not exist in static game process; (2) the rate of adopting prefabricated construction is affected by the level of penalties and subsidies; (3) dynamic incentive strategies can better improve the stability of the evolutionary game process; and (4) the rational range of incentive rate can be obtained. Findings of this study facilitate governments to formulate and improve the incentive strategies of prefabricated construction, thus boosting the development of construction industrialization.
\end{abstract}

\section{Introduction}

Prefabricated construction refers to an advanced construction technology, similar to "building blocks," which involves manufacturing building components in factories before assembling at construction sites [1, 2]. Widely propagated benefits of prefabricated construction include reductions in cost, construction period, health and safety risks, construction waste, energy consumption and carbon emissions, and a consequent improvement in quality, predictability, sustainability, whole-life performance, and profitability [3-9]. Because of its significant socio-economic and environmental benefits, prefabricated construction is considered as an important approach to achieve sustainable construction and building industrialization [10]. However, current application of prefabricated construction in China is still at the development stage compared with most western countries. The cost of prefabricated construction is usually higher than traditional cast-in-place construction methods due to the unsound standard system, weak modular design ability, and low efficiency for scale production $[11,12]$. It is estimated that using prefabricated construction may lead to an incremental construction cost of about $260 \mathrm{CNY}$ per unit construction area $\left(\mathrm{m}^{2}\right)[13,14]$. Most contractors are unwilling to adopt prefabricated construction in order to pursue the maximization of economic benefits [15]. Governments' incentive policies can reduce cost and risks of contractors to apply prefabricated construction. Therefore, it 
is essential for the government to play a leading role in the process of deeply promoting prefabricated construction.

China's central and provincial governments have formulated and implanted a set of policies targeted to promote prefabricated construction [16]. As far back as 2012, the Ministries of Housing and Urban-Rural Development (MOHURD) and Ministries of Finance (MOF) made a strategic objective that the rate of prefabricated buildings should account for over $30 \%$ of new buildings by 2020. In 2017, the "13th Five-Year Prefabricated Building Action Plan" and supporting management measures were further formulated. In 2019, MOHURD pointed out the major work that was to be undertaken in 2019 and highlighted the promotion of prefabricated construction once again. Meanwhile, provincial governments have as well issued a series of incentive policies including land policies, fiscal and tax policies, and building area subsidy policies to support the future development of prefabricated construction [2]. Although the central and provincial governments have issued many supporting policies, generally, these policies are sometimes incomplete, unclear, and lack of operability. This is because these policies often lack not only sufficient scientific evidence to support their rationality but also a corresponding disciplinary mechanism to guarantee their implantation. Therefore, from the perspective of governments, how to formulate optimal incentive policies for contractors adopting prefabricated construction is an important problem to be addressed urgently.

Governments and contractors are two main parties involved in promotion of prefabricated construction $[17,18]$. In order to optimize the incentive policies, the identification of key factors influencing collaborations and conflicts between governments and contractors and the decision process of both parties should be investigated. Game theory considers the costs and benefits of both parties in making different decisions and tries to find a balance between their interests to achieve a win-win situation [19]. It can help to explain behavioural relations between governments and contractors in the prefabricated construction promotion process. Early studies mainly used classical statistic game theory to model the interaction between governments and contractors for prefabricated construction promotion. They are based on an essential hypothesis, that is, the agents are completely rational and intelligent. This means that governments and contractors can always obtain complete information and make the best decision [20-22]. But, in fact, both parties behave as bounded rational agents in prefabricated construction promotion, and their information is either not symmetric. This means they cannot always make the best decision under limited information. Therefore, they will change their strategies dynamically by observing and comparing payoff with others and then adjust their strategies in repetitious games. This is not consistent with the basic hypothesis in classical statistic game theory. Evolutionary game theory, combing game theory and dynamic evolution process analysis, focuses more on the dynamics of strategy change and aims to find stable strategies in problems with conflict of interests [23]. It can overcome shortcomings of classical statistic game theory when analysing the bounded rationality of agents and the dynamic decision-making process of game playing [24-26]. Thus, evolutionary game theory is more suitable for studying the long-term dynamic game between governments and contractors for prefabricated construction promotion in China.

In fact, there have been many studies applying evolutionary game theory to investigate the promotion of prefabricated construction. For example, Qi et al. [27] applied evolutionary game theory to analyse the economic relationship between major stakeholders in the process of prefabricated construction promotion including governments, project developers, and prefabricated component manufacturers. Chen et al. analysed [28] the evolutionary strategic decision-making behaviour of project developers and consumers in the process of government's implementation of incentive policies and puts forward some strategic suggestions to realize pareto-optimal equilibrium. Jin et al. [29] further developed a tripartite evolutionary game model of government-contractor-consumer and concluded that the government should encourage contractors adopting prefabricated construction from tax preferences, financial subsidies, and other aspects to make the game evolve in the direction of advantageous to the development of market and industry. All these studies help to understand the dynamic interaction between stakeholders when promoting prefabricated construction and provide decision-making reference for governments [24-29]. However, they usually failed to intuitively simulate and show the dynamic game process and evolution results due to limitations of the evolutionary game theory approach.

The System Dynamics (SD) approach, introduced by Forrester [31] in the 1960s at Massachusetts Institute of Technology, is regarded as a structural modelling technique capable of understanding, simulating, and analysing complex systems, which is currently widely applied in various fields including social science, engineering, economics, and management. The evolutional game process can be also considered as a complex system consisting of an interactive structure and transformed into an SD model in the form of stock-flow diagram [31]. Some studies have applied SD to analyse the interactive structure of the evolutionary game process and got good results $[32,33]$. However, there are few studies combining the SD approach with the evolutionary game to study the interactive relationship between governments and contractors in the promotion of prefabricated construction.

To address the research gap, this paper aims to develop an SD-enabled evolutionary game simulation model on the government incentive strategy of prefabricated construction using Vensim software package. The developed model will be applied to investigate the behaviour rules of governments and contractors in prefabricated construction promotion and ascertain their effects on each other. The innovation of this study mainly lies in two aspects: the first is to investigate the role of government in promotion of prefabricated construction through analysing the dynamic decisionmaking process of both governments and contractors; the second is the application of SD theory for evolutionary game simulation, which can intuitively illustrate agents' dynamic 
interactions. The developed model is valuable as a tool for assessing the dynamic effects of government policies on the promotion of prefabricated construction ahead of implementation, which can provide references for policy designers.

\section{Evolutionary Game Analysis}

In the current application of prefabricated construction in China, two parties with asymmetric information behave as bounded rational players. Furthermore, the parties cannot eternally make the appropriate strategies under limited information. During reduplicative game, parties choose and adjust their strategies dynamically by calculating and comparing their total benefits. Thus, evolutionary game theory is accepted to analyse the relationship and behaviours of two main stakeholders.

2.1. Game Matrix Development. Respecting the current prefabricated construction industry in China, the game relationship of the two parties of the prefabricated construction promotion, i.e., the construction contractor (CC) and the local government (LG), is analysed. The CC is incentivized or penalized by the LG in its decision process of adopting construction technologies. Its strategies are composed of adopting prefabricated construction or traditional cast-in-place construction. To pursue the maximization of economic benefits, the CC can choose to adopt the prefabricated construction or not by anticipating its own expenditure and revenue. The LG stimulates the CC to adopt prefabricated construction by incentive or penalty policies. Its strategies can be performed as incentive policies or no incentive policies for the sake of generally economic and ecological sustainability. The LG's ability of supervision is assumed to be sufficiently powerful, that is, the LG could make immediate response and give the corresponding financial incentives or penalties to the contractors, respectively.

To conduct the choice strategy of the CC in the evolutionary game model, $x(0 \leq x \leq 1)$ is assigned as the rate of adopting prefabricated construction. If choosing prefabricated construction, the CC could gain the financial subsidy and other benefits (e.g., green corporate image). Accordingly, $B_{1}\left(B_{1}>0\right)$ and $B_{2}\left(B_{2}>0\right)$ represent the CC's economic and other benefit of adopting prefabricated construction, respectively. However, the cost of prefabricated construction is generally higher than the traditional cast-in-place construction method on account of its current defects (e.g., the incomplete standard system and low efficiency for scale production). In this instance, $C_{1}\left(C_{1}>0\right)$ represents the CC's cost of adopting prefabricated construction. Additionally, the $\mathrm{CC}$ will be punished when not adopting prefabricated technology, in which $P(P>0)$ represents the CC's penalties of not adopting prefabricated construction.

The LG chooses $y(0 \leq y \leq 1)$ as its strategy, in which $y$ is designated as the incentive rate. This variable comprehensively refers to the incentive threshold. Since the popularity of prefabricated construction is limited, the LG needs to propagandize it, which is another cost besides the cost of incentive pay. In this instance, $C_{2}\left(C_{2}>0\right)$ and $C_{3}\left(C_{3}>0\right)$ represent the LG's cost of subsidies and propagandizing, respectively. Moreover, if the prefabricated construction is widely accepted, the LG will facilitate other benefit (e.g., resource saving, environmental protection, and government credibility). In this case, $B_{3}\left(B_{3}>0\right)$ represents the LG's other benefits for performing prefabricated construction. Therefore, the game matrix between the CC and LG for prefabricated construction promotion can be obtained (Table 1).

2.2. Game Equation Establishment. Bounded rational players tend to choose beneficial strategies dynamically, and they will achieve a balance in the process of calculating and comparing. Accordingly, the CC's expected benefits of adopting prefabricated construction or not can be calculated through the following equations:

$$
U_{C Y}=y-C_{1}+B_{1}+B_{2}+C_{2}+(1-y)\left(-C_{1}+B_{1}+B_{2}\right),
$$

$$
U_{C N}=y-P+(1-y)(0)
$$

where $U_{C Y}$ and $U_{C N}$ represent the CC's expected benefits of adopting prefabricated construction and not, respectively. Therefore, the average benefits of the CC can be figured out using the following equation:

$$
\bar{U}_{C}=x U_{C Y}+(1-x) U_{C N} .
$$

The CC is inclined to detect the higher benefits as its final strategy. According to the replicator dynamics, the change rate of $x$ can be expressed as the following equation:

$$
\frac{\mathrm{d} x}{\mathrm{~d} t}=x\left(U_{Y}-\bar{U}\right) .
$$

By defining $F(x)=(\mathrm{d} x / \mathrm{d} t)$ and substituting equations (1) and (2) into equation (4), the following equation can be obtained:

$$
\begin{aligned}
F(x) & =\frac{\mathrm{d} x}{\mathrm{~d} t}=x(1-x)\left(U_{C Y}-U_{C N}\right) \\
& =x(1-x)\left[y\left(C_{2}+P\right)-C_{1}+B_{1}+B_{2}\right] .
\end{aligned}
$$

Similarly, the change rate of $y$ can be obtained as follows:

$$
F(y)=\frac{\mathrm{d} y}{\mathrm{~d} t}=y\left(U_{G Y}-\bar{U}_{G}\right)=y(1-y)\left[x\left(-C_{2}-P\right)-C_{3}+P\right] .
$$

Consequently, the evolution game between the CC and LG can be represented by a replicated dynamic equation set:

$$
\left\{\begin{array}{l}
F(x)=x(1-x)\left[y\left(C_{2}+P\right)-C_{1}+B_{1}+B_{2}\right] \\
F(y)=y(1-y)\left[-x\left(C_{2}+P\right)-C_{3}+P\right]
\end{array}\right.
$$

The equation set reflects the speed and orientation of CC and LG strategy adjustment. When each equation is equal to 
TABLE 1: Game matrix between the CC and LG for prefabricated construction promotion.

\begin{tabular}{cccc}
\hline & & LG & \\
& & Incentive policies $(y)$ & No incentive policies $(1-y)$ \\
\hline CC & Adopting prefabricated construction $(x)$ & $\left(-C_{1}+B_{1}+B_{2}+C_{2},-C_{2}-C_{3}+B_{3}\right)$ & $\left(-C_{1}+B_{1}+B_{2} B_{3}\right)$ \\
& Not adopting prefabricated construction $(1-x)$ & $\left(-P,-C_{3}+P\right)$ & $(0,0)$ \\
\hline
\end{tabular}

zero, the parties will not change their adopted strategies, and the evolutionary game of prefabricated construction promotion reaches the relatively balanced state.

\subsection{Stability Analysis}

2.3.1. CC's Pure Strategy. Stability analysis of the CC's pure strategy is conducted based on equation (5).

Given that $y=\left(\left(C 1-B_{1}-B_{2}\right) /\left(C_{2}+P\right)\right), F(x)=0$. In this case, the CC has states of stability at any value of $x$.

Otherwise, when $F(x)=0$, the two equilibrium solutions of the CC's strategy-replicated dynamics equation can be obtained as

$$
\begin{aligned}
& x=0, \\
& x=1 .
\end{aligned}
$$

The derivative of $F(x)$ can be calculated through the following equation:

$$
\frac{\partial F(x)}{\partial x}=(1-2 x)\left[y\left(C_{2}+P\right)-C_{1}+B_{1}+B_{2}\right]
$$

Only when $(\partial F(x) / \partial x)<0$, evolutionary stable strategy exits. Therefore, we have to split in the following situations:

When $C_{1}-B_{1}-B_{2}<0$, permanently, $y>\left(\left(C_{1}-\right.\right.$ $\left.\left.B_{1}-B_{2}\right) /\left(C_{2}+P\right)\right)$. The evolutionary stable strategy is $x=1$. In this case, the CC, as a bounded rational agent, chooses the strategy of adopting prefabricated construction.

When $C_{1}-B_{1}-B_{2}>C_{2}+P$, permanently, $y<\left(\left(C_{1}-\right.\right.$ $\left.\left.B_{1}-B_{2}\right) /\left(C_{2}+P\right)\right)$. The evolutionary stable strategy is $x=0$. In this case, the CC chooses the strategy of not adopting prefabricated construction.

When $0<C_{1}-B_{1}-B_{2}<C_{2}+P$, there are two alternatives:

When $y>\left(\left(C_{1}-B_{1}-B_{2}\right) /\left(C_{2}+P\right)\right)$, then $\partial F(x) /$ $\left.\partial x\right|_{x=0}>0, \partial F(x) /\left.\partial F(x)\right|_{x=1}<0$. In this case, the evolutionary stable strategy is $x=1$. The CC chooses the strategy of adopting prefabricated construction.

When $y<\left(\left(C_{1}-B_{1}-P 1\right) /\left(C_{2}+P\right)\right)$, then $\partial F(x) /$ $\left.\partial x\right|_{x=0}<0, \partial F(x) /\left.\partial x\right|_{x=1}>0$, In this case, the evolutionary stable strategy is $x=0$. The CC chooses the strategy of not adopting prefabricated construction.

2.3.2. LG's Pure Strategy. Stability analysis of the LG's pure strategy is conducted based on equation (6).
Given that $x=\left(\left(P-C_{3}\right) /\left(C_{2}+P\right)\right), F(y)==0$. In this case, the LG has states of stability at any value of $y$.

Otherwise, when $F(y)=0$, the two equilibrium solutions of the LG's strategy replicated dynamics equation can be obtained as

$$
\begin{aligned}
& y=0, \\
& y=1
\end{aligned}
$$

The derivative of $F(y)$ can be calculated through the following equation:

$$
\frac{\partial F(y)}{\partial y}=(1-2 y)\left[-x\left(C_{2}+P\right)-C_{3}+P\right] .
$$

When $P-C_{3}<0$, permanently, $x>\left(\left(P-C_{3}\right) /\left(C_{2}+P\right)\right)$. The evolutionary stable strategy is $y=0$. In this case, the LG, as a bounded rational agent, chooses the strategy of no incentive policies.

When $P-C_{3}>0$, there are two alternatives:

When $x>\left(\left(P-C_{3}\right) /\left(C_{2}+P\right)\right)$, then $\partial F(y) /\left.\partial y\right|_{y=0}<0$, $\partial F(y) /\left.\partial y\right|_{y=1}>0$. In this case, the evolutionary stable strategy is $y=0$. The LG chooses the strategy of no incentive policies.

When $x<\left(\left(P-C_{3}\right) /\left(C_{2}+P\right)\right)$, then $\partial F(y) /\left.\partial y\right|_{y=0}>0$, $\partial F(y) /\left.\partial y\right|_{y=1}<0$. In this case, the evolutionary stable strategy is $y=1$. The LG chooses the strategy of always subsiding the CC for adopting prefabrication.

2.3.3. Mixed Strategies. In fact, the cost of adopting prefabricated construction is usually higher than its benefits for the CC. The LG will also avoid extreme situations by raising the penalties. Therefore, the abovementioned evolutionary stable states in pure strategy analysis hardly occur. In this section, we mainly discuss the game stability of CC's and LG's mix strategies under $P-C_{3}>0$ and $C_{2}+P>-C_{1}+B_{1}+B_{2}>0$.

We defined $X=\left(\left(P-C_{3}\right) /\left(C_{2}+P\right)\right), Y=\left(\left(C_{1}-B_{1}-B_{2}\right) /\right.$ $\left.\left(C_{2}+P\right)\right)$. According to replicated dynamic equation set equation (7), when $0 \leq X \leq 1,0 \leq Y \leq 1$, there exit five Nash equilibrium solutions as follows:

$$
(0,0),(0,1),(1,0),(1,1),(X, Y) .
$$

According to Friedman's theory, the stability of the evolutionary game system under equilibrium solutions can be obtained by analysing the determinant and trace of Jacobian matrix $J$. When the Jacobian matrix's determinant $\operatorname{det}(J)>0$ and its trace $\operatorname{tr}(J)<0$, the equilibrium solution is 
the evolutionary stable strategy. The Jacobian matrix of equation (7) is shown as the following equation:

$$
J=\left[\begin{array}{ll}
\frac{\partial F(x)}{\partial x} & \frac{\partial F(x)}{\partial y} \\
\frac{\partial F(y)}{\partial x} & \frac{\partial F(y)}{\partial y}
\end{array}\right]=\left[\begin{array}{cc}
(1-2 x)\left[y\left(C_{2}+P\right)-C_{1}+B_{1}+B_{2}\right] & x(1-x)\left(C_{2}+P\right) \\
-y(1-y)\left(C_{2}+P\right) & (1-2 y)\left[-x\left(C_{2}+P\right)-C_{3}+P\right]
\end{array}\right]
$$

Table 2 shows the results of stability analysis based on the Jacobian matrix.

It can be found this game system has four saddle point and one central point. $(X, Y)=((X, Y)=(P-$ $\left.\left.C_{3}\right) /\left(C_{2}+P\right),\left(C_{1}-B_{1}-B_{2}\right) /\left(C_{2}+P\right)\right)$. The corresponding two characteristic roots are a pair of imaginary roots. According to Taylor's research [34], the Nash equilibrium solution $(X, Y)$ is an evolutionary stable solution, but it is not asymptotically stable.

\section{System Dynamics Simulation}

3.1. Model Development. According to evolutionary game theory, the parties will continuously observe and compare payoff of all possible strategies and, then, repetitiously adjust their strategies. The traditional stability analysis approach fails to visibly simulate and show the game process and results. The SD model enables to simulate the behaviour of complicated systems over time by analysing the causality and interaction among all elements involved in the system. It can well describe and simulate the evolutionary game process under bounded rationality because of its advantages in addressing problems with incomplete information. Therefore, the evolutionary game between CC and LG for prefabricated construction promotion under mixed strategies can be expressed by a SD model (Figure 1). The SD model is developed in Vensim PLE (Version 5.8b). There are 2 level variables, 2 rate variables, 14 intermediate variables, and 9 external variables with the established model. Level variables refer to the accumulations within the system; Rate variables involve the flows in the system due to the decision-making process; auxiliary variables represent transition variables by calculation, (i.e., expected cost and benefit of governments and contractors when making different decisions); and external variables are constants involved in the system.

Based on the developed evolutionary game SD model, the existence or absence of evolutionary stable strategy can be analysed. In addition, the behaviour changes of both parties can be predicted by varying external variables.

3.2. Parameters Setting. We set the initial time $=0$, final time $=50$, and time step $=0.0078125$. The unit for time is year. The initial values of external variables are set as Table 3 based on an expert interview in Shanghai. Thus, the equilibrium solution of mixed strategy $(X, Y)=\left(\left(\left(P-C_{3}\right) /\right.\right.$ $\left.\left.\left(C_{2}+P\right)\right),\left(\left(C_{1}-B_{1}-B_{2}\right) /\left(C_{2}+P\right)\right)\right)=(0.25,0.2)$.

3.3. Model Validation. Figure 2 shows the evolutionary game process and results under the equilibrium solution of mixed strategy $(0.25,0.2)$. It indicates that both the CC and LG do not change their initial strategies. This means the evolutionary game is in a relatively balanced state.

However, this state is unsteady. Figure 3(a) shows the simulation results when the $x$ in Figure 2 from 0.25 to 0.15 at time $=5$. It shows the balanced state is broken. The LG also immediately changes its strategy, and strategy selections of the CC and LG fluctuate repeatedly. The parties start a periodic game. When changing the horizontal coordinate and ordinate into the rate of adopting prefabricated construction for the CC and the incentive rate for the LG, respectively, Figure 3 can be redrawn as Figure 3(b). It can be seen that the trace of systematic evolution is a close orbit loop, which is not across the central point and is void of limit cycle. Similar results can be also obtained from other pure strategies. It again indicates that no evolutionary stability strategy is presented in the static game process. This is consistent with the stability analysis in Section 2 and verifies the rationality of the developed SD model.

3.4. Sensitivity Analysis. Unexpected fluctuations make it difficult to guarantee the effectiveness of prefabricated construction promotion. Thus, the fluctuation should be controlled. External variables play important roles affecting the fluctuations in the game model. Among these variables, subsidies and penalties are relatively easier to adjust in reality. Thus, their impacts on the game process are analysed based on the developed model.

Figure 4 shows the simulation results under baseline scenario, in which the initial values of $x$ and $y$ are set at 0.3 and 0.7 , respectively. It can be seen that the rate of adopting prefabricated construction gradually increases to the peak value at 0.75 in the third year. After that, it declines until reach the bottom in the 21st year. Then, it increases again and repeats the cycle fluctuations. The incentive rate also follows periodic fluctuations that is negatively correlated with the rate of adopting prefabricated construction. However, the strategy adjustment has obvious hysteresis quality. In addition, both $x$ and $y$ vary the most significantly in the beginning 4 years. Therefore, the simulation period is set at 4 years in sensitivity analysis. Next, we discussed 
TABLE 2: Evolutionary stability analysis based on the Jacobian matrix.

\begin{tabular}{lccr}
\hline Equilibrium solutions & $\operatorname{det}(J)$ & $\operatorname{tr}(J)$ & Results \\
\hline$(0,0)$ & - & Uncertainty & Saddle point \\
$(0,1)$ & - & Uncertainty & Saddle point \\
$(1,0)$ & - & Uncertainty & Saddle point \\
$(1,1)$ & - & Uncertainty & Saddle point \\
$(X, Y)$ & + & 0 & Central point \\
\hline
\end{tabular}

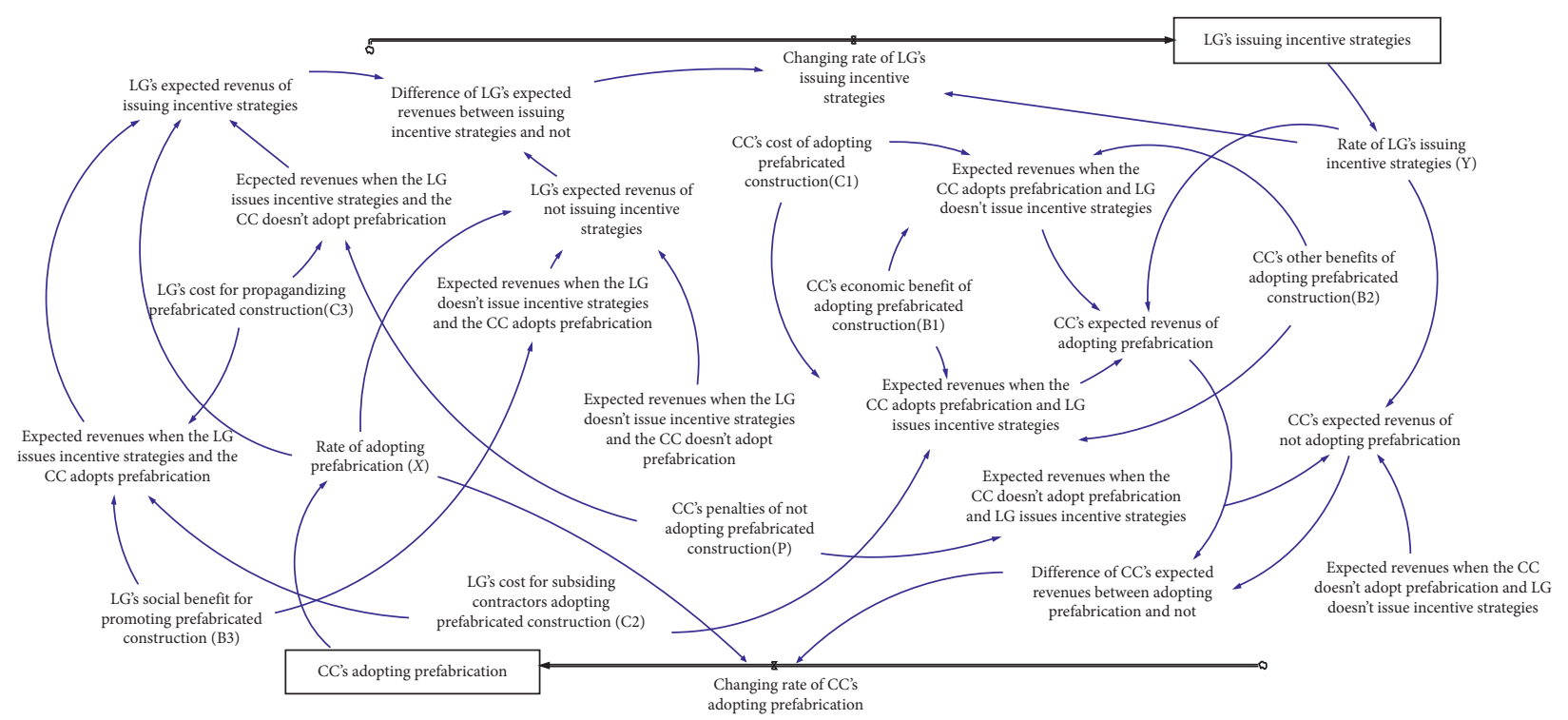

FIGURE 1: SD model of the evolutionary game between the CC and LG for prefabricated promotion.

TABLE 3: Initial values of external variables.

\begin{tabular}{lcc}
\hline Variables & Meaning of the variables & Initial values \\
\hline$C_{1}$ & The CC's cost of adopting prefabricated construction & 3 \\
$B_{1}$ & The CC's economic benefit of adopting prefabricated construction & 1.8 \\
$B_{2}$ & The CC's other benefits of adopting prefabricated construction & 0.8 \\
$P$ & The CC's penalties of not adopting prefabricated construction & 1 \\
$C_{2}$ & The LG's cost for subsiding contractors adopting prefabricated construction & 1 \\
$C_{3}$ & The LG's cost for propagandizing prefabricated construction & 0.5 \\
$B_{3}$ & The LG's social benefit for promoting prefabricated construction & 2 \\
\hline
\end{tabular}

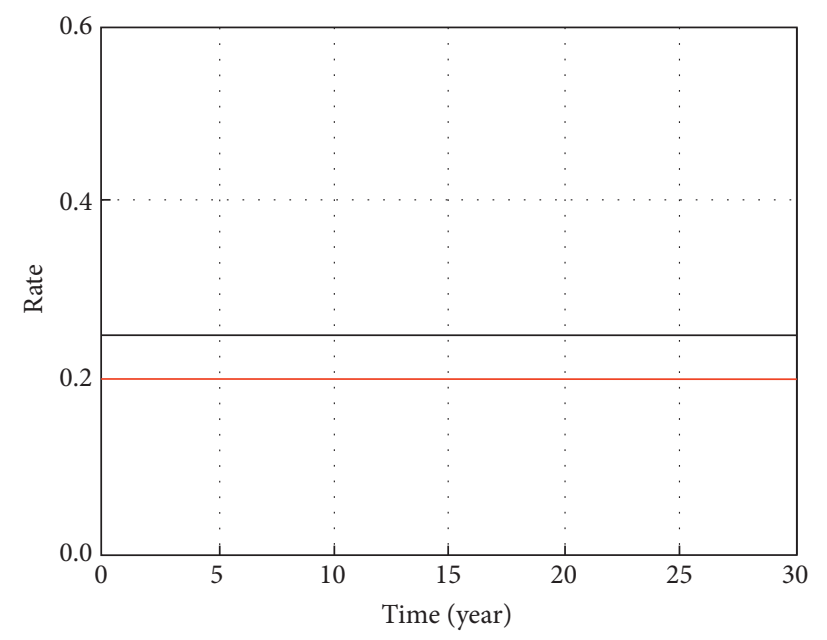

Rate of adopting prefabrication $(x=0.25)$
- Incentive rate $(y=0.2)$

FIGURE 2: Simulation results under the equilibrium solution of mixed strategy $(0.25,0.2)$. 


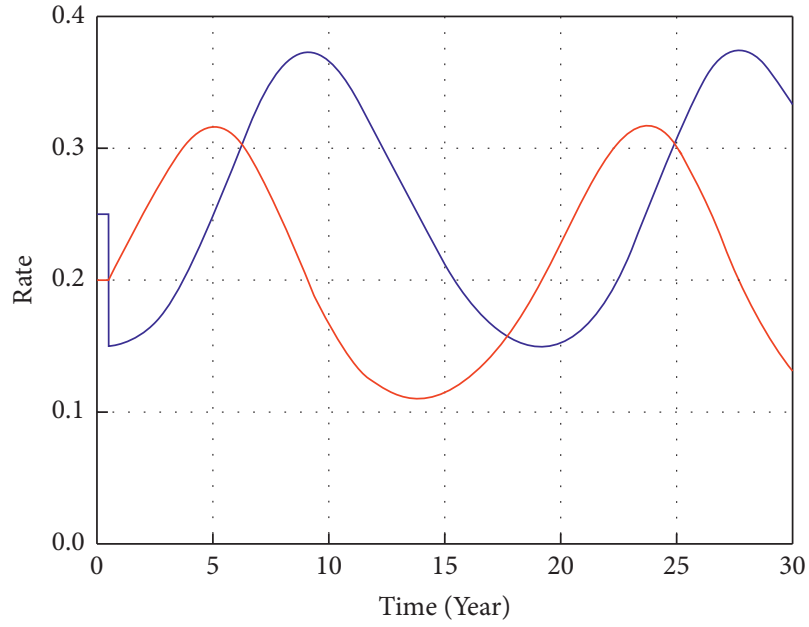

- Rate of adopting prefabrication $(x=0.25)$

Incentive rate $(y=0.2)$

(a)

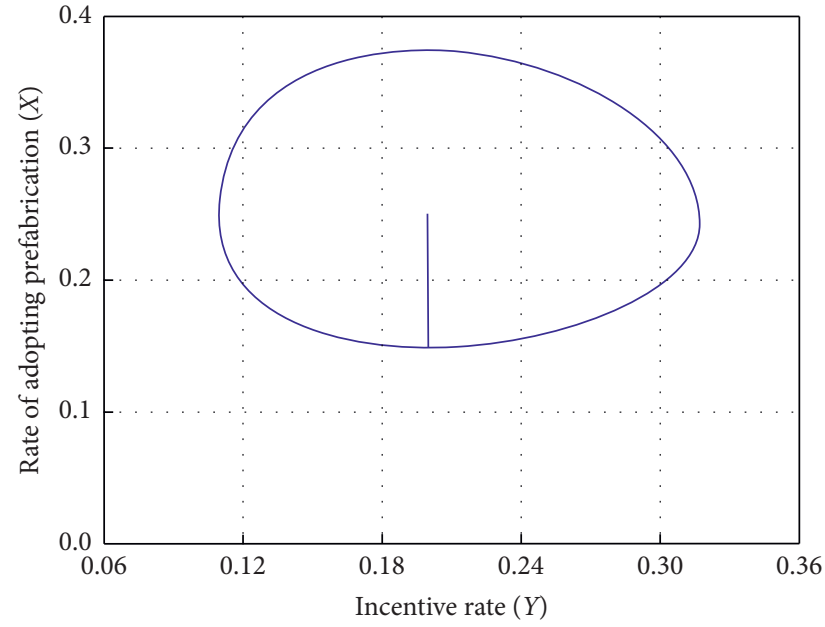

(b)

Figure 3: Simulation results when $x$ changes from 0.25 to 0.15 at time $=5$. (a) Simulation results after changing the initial strategy. (b) Trace of the systematic evolution strategy.

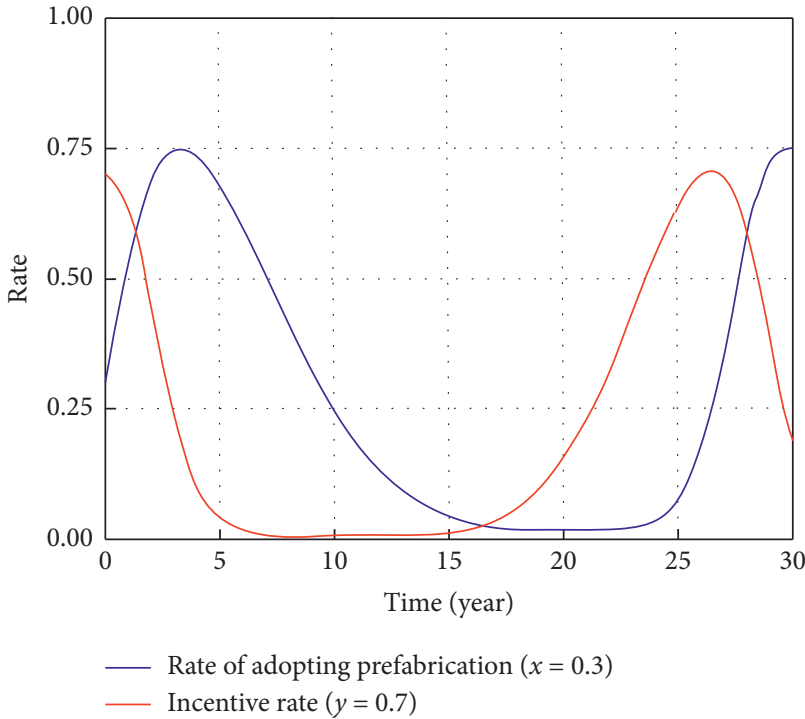

FIGURE 4: Simulation results under the baseline scenario.

impacts of subsidies and penalties on the rate of adopting prefabricated construction.

Figure 5 shows the evolutionary game process and results when the initial value of subsidies $C_{2}$ changes from 1 to 1.2 and 0.8 . According to the simulation results, the rate of adopting prefabricated construction increases to 0.75 firstly and, then, declines no matter what value of the subsidies is. This means changing subsidies cannot influence the peak value of the rate of adopting prefabricated construction. However, the higher subsidies are, the earlier the rate of adopting prefabricated construction reaches the peak value. This means, increasing the subsidies can help to promote prefabricated construction faster.

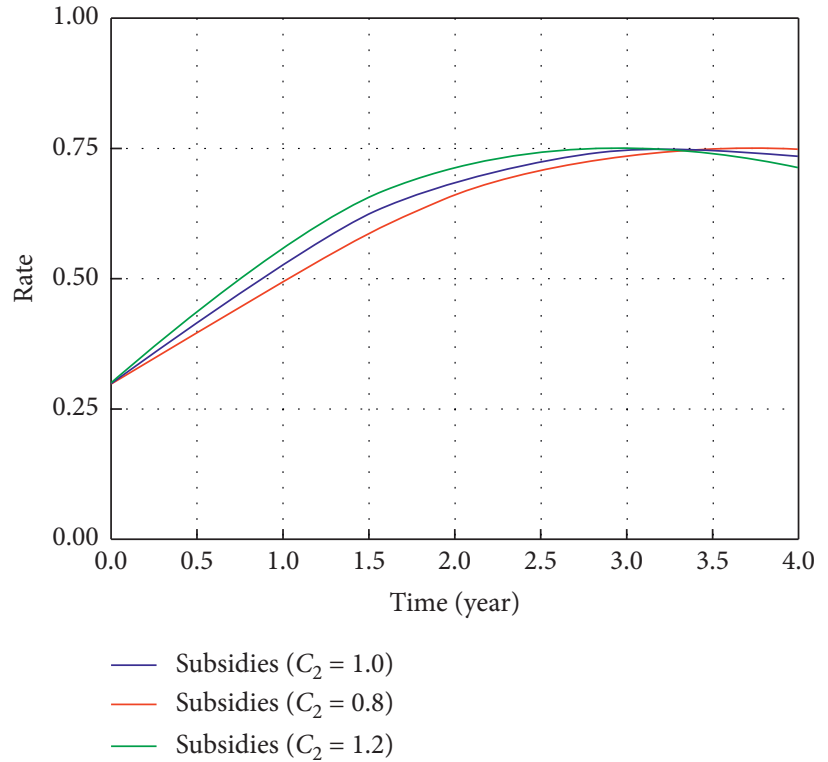

FIgURE 5: Sensitivity analysis on subsidies for adopting prefabricated construction.

Figure 6 shows the evolutionary game process and results when the initial value of penalties $P$ changes from 1 to 1.2 and 0.8 . It presents that the higher the penalties are, the higher the peak value of the adopting prefabricated construction rate is. However, it cannot obviously influence the time reaching the peak. The CC is more sensitive towards penalties compared with subsidies. However, prefabricated construction in fact cannot be effectively promoted by only imposing tougher penalties on CC owing to its recent emergence in China. Thus, its market occupancy should be 


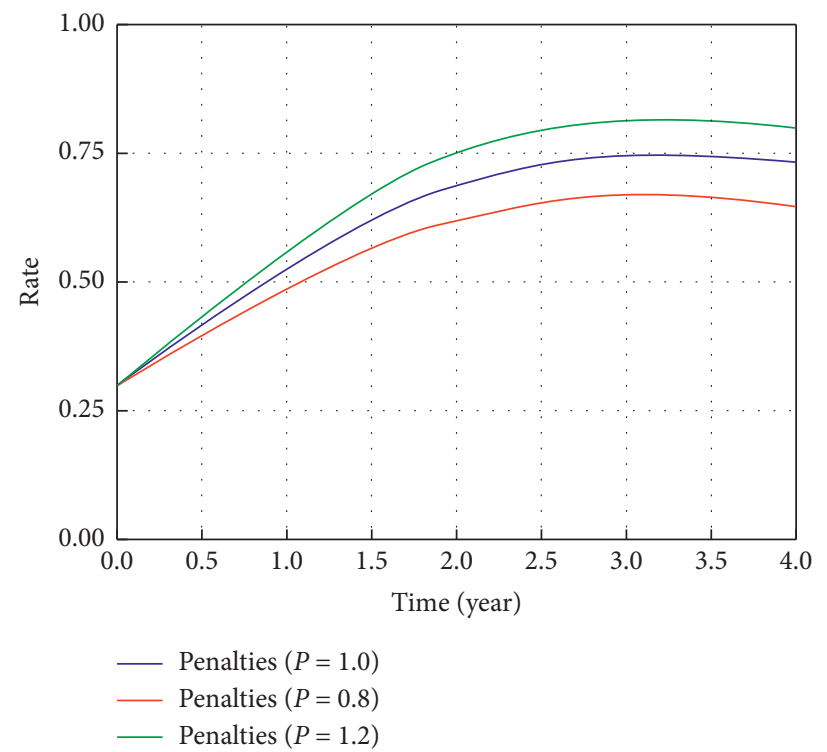

FIgURE 6: Sensitivity analysis on penalties for adopting prefabricated construction.

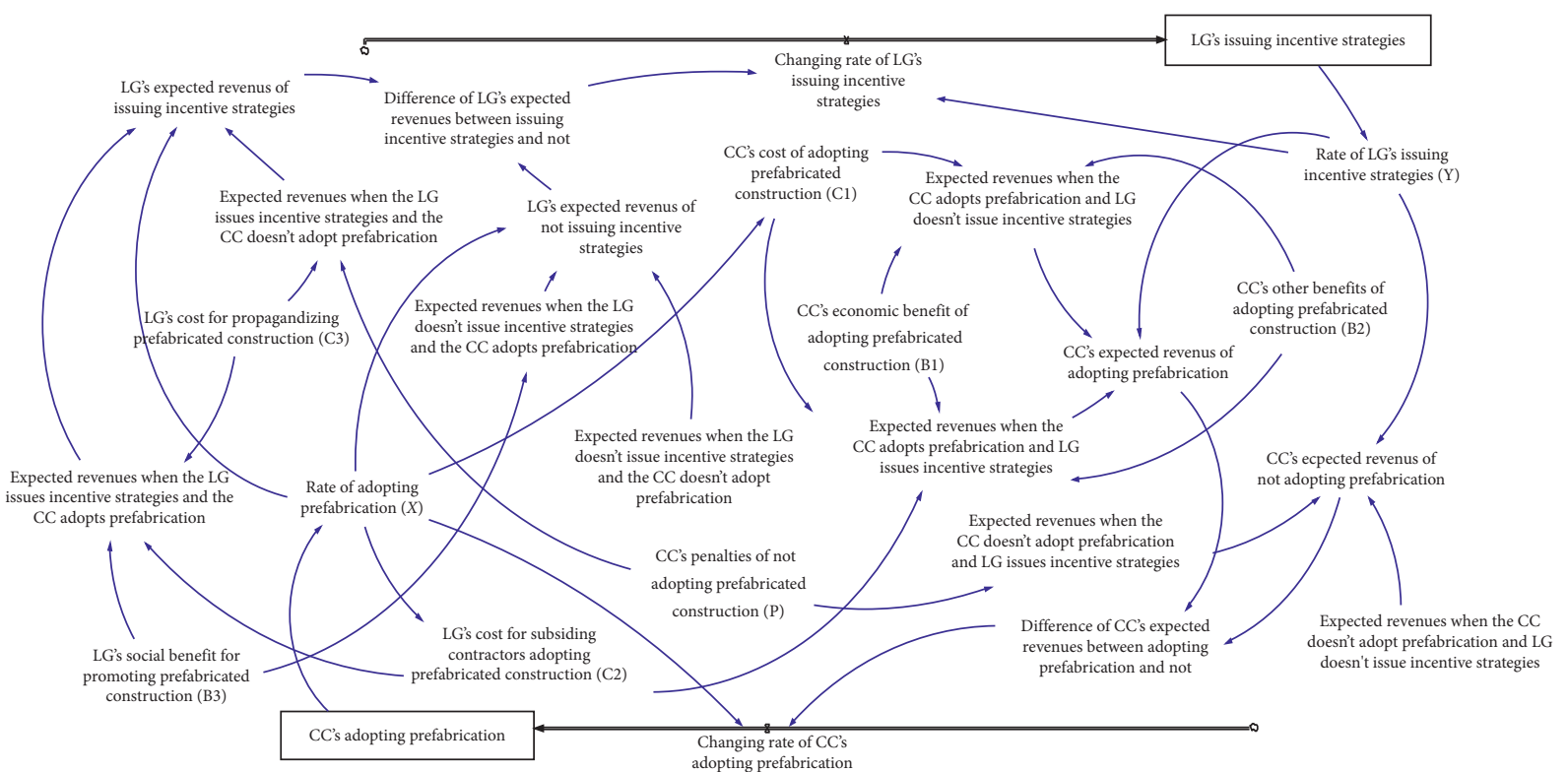

FIgURe 7: Modified SD model for dynamic incentive strategies.

promoted by incentive strategies organic combination subsidies with penalties.

\subsection{Model Modification for Dynamic Incentive Strategies.} Statistic incentive strategies can reduce and control the unexpected repeated fluctuations in the game process between the LG and CC to some degree, but it cannot eliminate the fluctuations. In fact, both the subsidies and penalties are usually not static. They will change with the promotion of prefabricated construction. In addition, the promotion of prefabricated construction will also reduce the production cost because of scale effects. Therefore, the model of dynamic incentive strategy can be established by correlating the relationship between the rate of adopting prefabricated construction and production cost in the following equations:

$$
\begin{aligned}
& C_{1}=3-0.5 x, \\
& X=\frac{P-C_{3}}{x C_{2}+P}, \\
& Y=\frac{C_{1}-B_{1}-B_{2}}{x C_{2}+P} .
\end{aligned}
$$

Therefore, the model in Figure 1 can be modified into Figure 7 for dynamic incentive strategies. 


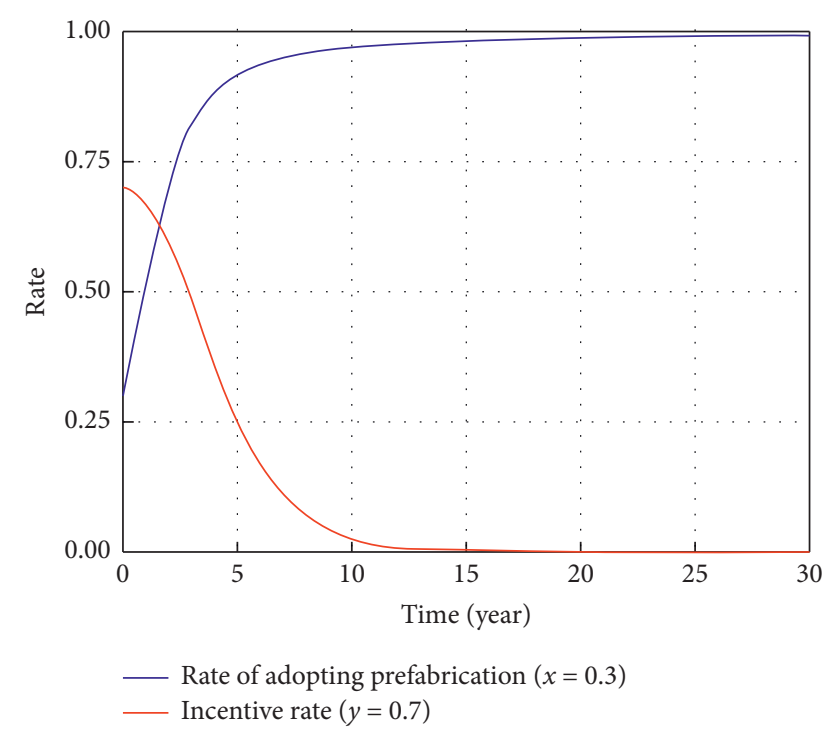

FIGURE 8: Simulation results of dynamic incentive strategies under the initial strategy $(x=0.3, y=0.7)$.

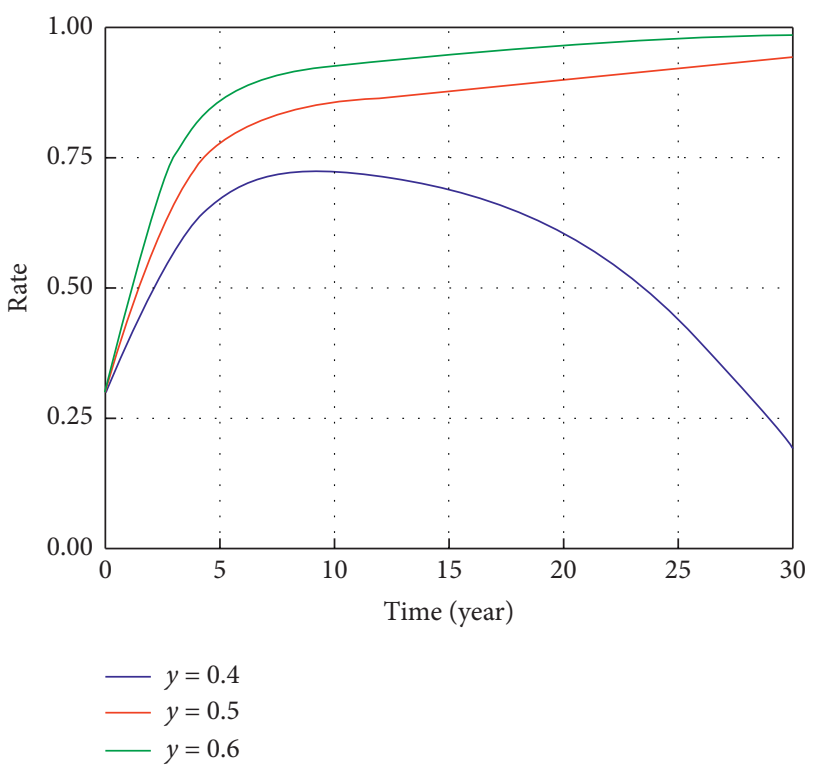

Figure 9: Simulation results under dynamic incentive strategies.

Figure 8 shows the simulation results from the modified SD model under the same initial strategy with Figure 4 $(x=0.3, y=0.7)$. By comparing Figure 9 and Figure 4 , it can be learnt that dynamic incentive strategies can better can better control the unexpected fluctuations and achieve an ideal stable state in the game process $(x=1, y=0)$.

Figure 9 compares changes of the rate of adopting prefabricated construction under different initial value of incentive rates (i.e., $y=0.4,0.5,0.6)$ when the initial rate of adopting prefabricated construction is set at 0.3 . When the initial incentive rate is low (0.4), the rate of adopting prefabricated construction increases and reaches the peak value of 0.73 in the 10th year and, then, decreases. The game cannot get an ideal stable state. However, when the initial incentive rate increases to 0.5 and 0.6 , the rate of adopting prefabricated construction goes up and eventually is close to the upper limit value of 1 without failing, indicating that the game process entering an ideal stable state. We can deduce that a critical value of initial incentive rate exits between 0.4 and 0.5 when the initial rate of adopting prefabricated construction is set at 0.3 . Only when the initial incentive rate exceeds the threshold, the evolutionary game can get an ideal stable state. The higher the initial incentive rate is, the faster the rate of adopting prefabricated construction converges to 1 , and the game enters the stable state. It can be found that the crucial value is around 0.45 through future simulations. The threshold point of the dynamic incentive strategies provides a quantitative reference for the government's decision making.

\section{Conclusions}

This study developed a simulation model of the evolutionary game between governments and contractors for promoting prefabricated construction based on SD theory. The model is validated through stability analysis and main factors influencing the game process are identified through sensitivity analysis. To further optimize the incentive strategies, the model is further modified for dynamic incentive strategies by associating the government's incentive rate with contractors' rate of adopting prefabricated construction. The critical value of initial incentive is found. Main conclusions can be drawn as follows:

(1) There is no evolutionary stable strategy in static game process

(2) Both the level of penalties and subsidies influence the rate of adopting prefabricated construction while the impacts of penalties are more obvious

(3) Dynamic incentive strategies can better control the unexpected fluctuations and improve the stability of evolutionary game process

(4) A threshold of the initial incentive rate exists in the dynamic incentive strategies

Only when it exceeds the threshold, the game process can get an ideal stable state. Findings from this study can provide decision-making references for governments to optimize policy systems and further promote prefabricated construction. However, data used in this study are collected by reviewing the government report and interviewing experts in Shanghai. More data in other provinces should be collected to future validate the model.

\section{Data Availability}

All data generated or used during the study appear in the submitted manuscript.

\section{Conflicts of Interest}

The authors declare that there are no conflicts of interest regarding the publication of this paper. 


\section{Acknowledgments}

This research was supported by China Innovation Funding (2017YFB1201204), the National Natural Science Foundation of China (71942006), Nature Science Fund of Hunan Province (2019JJ40407), Nature Science Fund of Anhui Province (2008085QE245), and University Provincial Key Natural Science Research Projects of Anhui Province (KJ2019A0747).

\section{References}

[1] Z. Li, G. Q. Shen, and X. Xue, "Critical review of the research on the management of prefabricated construction," Habitat International, vol. 43, pp. 240-249, 2014.

[2] J. L. Hao, B. Cheng, and W. Lu, "Carbon emission reduction in prefabrication construction during materialization stage: a BIM-based life-cycle assessment approach," Science of the Total Environment, vol. 723, Article ID 137870, 2020.

[3] Z. Li, G. Q. Shen, and M. Alshawi, "Measuring the impact of prefabrication on construction waste reduction: an empirical study in China," Resources Conservation and Recycling, vol. 91, pp. 27-39, 2014.

[4] B. Cheng, J. Li, V. W. Tam, M. Yang, and D. Chen, "A BIMLCA approach for estimating the greenhouse gas emissions of large-scale public buildings: a case study," Sustainability, vol. 12 , no. 2 , p. $685,2020$.

[5] J. P. Couto, P. Mendonca, and A. P. Reis, "Prefabricated building systems: evaluation of the construction practitioners' perception on the environmental and economic benefits," Environmental Engineering and Management Journal, vol. 17, no. 9, pp. 2103-2115, 2018.

[6] W. Ma, Y. Li, K. Ding et al., "Mechanical properties of new dry-type beam-column bolt connection join," Sustainability, vol. 11, no. 12, p. 334, 2019.

[7] X. Cao, X. Li, Y. Zhu, and Z. Zhang, "A comparative study of environmental performance between prefabricated and traditional residential buildings in China," Journal of Cleaner Production, vol. 103, pp. 131-143, 2015.

[8] Z. Wang, L. Li, and Y. Zhang, "Bond-slip model considering freeze-thaw damage effect of concrete and its application," Engineering Structures, vol. 201, Article ID 109831, 2019.

[9] Z. Wang, L. Li, and Y. Zhang, "Reinforcement model considering slip effect," Engineering Structures, vol. 198, Article ID 109493, 2019.

[10] V. W. Y. Tam, C. M. Tam, S. X. Zeng, and W. C. Y. Ng, "Towards adoption of prefabrication in construction," Building and Environment, vol. 42, no. 10, pp. 3642-3654, 2007.

[11] J. Hong, G. Q. Shen, Z. Li, B. Zhang, and W. Zhang, "Barriers to promoting prefabricated construction in China: a cost-benefit analysis," Journal of Cleaner Production, vol. 172, pp. 649-660, 2018.

[12] G. Wu, R. Yang, L. Li, X. Bi, B. Liu, and S. Li, "Factors influencing the application of prefabricated construction in China: from perspectives of technology promotion and cleaner production," Journal of Cleaner Production, vol. 219, pp. 753-762, 2019.

[13] Y. Qi, S. Chang, Y. Ji, and K. Qi, "BIM-based incremental cost analysis method of prefabricated buildings in China," Sustainability, vol. 10, no. 11, p. 4293, 2018.

[14] W. Chen, X. Jiang, Y. Q. Yu, and H. Y. Fu, "Measurement of incremental cost of prefabricated constructio," Finance and Accounting Monthly, vol. 826, no. 6, pp. 77-83, 2018.
[15] J. Wang, Z. Li, and V. W. Y. Tam, "Critical factors in effective construction waste minimization at the design stage: a Shenzhen case study, China," Resources Conservation and Recycling, vol. 82, pp. 1-7, 2014.

[16] W. S. Lu, K. Chen, F. Xue, and W. Pan, "Searching for an optimal level of prefabrication in construction: an analytical framework," Journal of Cleaner Production, vol. 201, pp. 236-245, 2018.

[17] Y. Zhai, Y. Fu, G. Xu, and G. Huang, "Multi-period hedging and coordination in a prefabricated construction supply chain," International Journal of Production Research, vol. 57, no. 7, pp. 1949-1971, 2019.

[18] Y. Liu, J. Dong, and L. Shen, "A conceptual development framework for prefabricated construction supply chain management: an integrated overview," Sustainability, vol. 12, no. 5, p. 1878, 2020.

[19] A. Baniak and I. Dubina, "Innovation analysis and game theory: a review," Innovation Management, Policy \& Practice, vol. 14, no. 2, pp. 178-191, 2012.

[20] Q. Shi, J. Zhu, M. Hertogh, and Z. Sheng, "Incentive mechanism of prefabrication in mega projects with reputational concerns," Sustainability, vol. 10, no. 4, p. 1260, 2018.

[21] J. Zhu, Q. Shi, P. Wu, Z. Sheng, and X. Wang, "Complexity analysis of prefabrication contractors' dynamic price competition in mega projects with different competition strategies," Complexity, vol. 2018, Article ID 5928235, 9 pages, 2018.

[22] Q. Shi, J. Zhu, and Q. Li, "Cooperative evolutionary game and applications in construction supplier tendency," Complexity, vol. 2018, Article ID 8401813, 13 pages, 2018.

[23] J. Hofbauer and K. Sigmund, "Evolutionary game dynamics," Bulletin of the American Mathematical Society, vol. 40, no. 4, pp. 479-519, 2003.

[24] T. Feng, S. Tai, C. Sun, and Q. Man, "Study on cooperative mechanism of prefabricated producers based on evolutionary game theory," Mathematical Problems in Engineerin, vol. 2017, Article ID 1676045, 6 pages, 2017.

[25] Q. Chen, P. H. Liu, and C. T. Chen, "Evolutionary game analysis of government and enterprises during promotion process of prefabricated construction," Journal of Interdisciplinary Mathematics, vol. 20, no. 6-7, pp. 1587-1593, 2017.

[26] X. Li, C. Wang, A. Alashwal, and S. Bora, "Game analysis on prefabricated building evolution based on dynamic revenue risks in China," Journal of Cleaner Production, vol. 267, Article ID 121730, 2020.

[27] B. K. Qi, L. C. Jin, D. Wang, and D. Zhang, "Research of design of government compensation mechanism of assembly building based on game theory," Architecture Technology, vol. 48, no. 8, pp. 835-837, 2017.

[28] Y. L. Chen, S. Z. Lin, and Y. Z. Shi, "Evolutionary game on incentive policy for prefabrication," Journal of Civil Engineering and Management, vol. 35, no. 2, pp. 155-160, 2018.

[29] Z. Y. Jin, X. H. Qiu, J. Y. Sun, Y. Q. Wang, and X. H. Kang, "Research on economic incentive policy for prefabrication," Construction Economy, vol. 41, no. 1, pp. 22-28, 2020.

[30] J. W. Forrester, Industrial Dynamics, Pegasus Communications, Waltham, MA, USA, 1961.

[31] S. Gu, P. Zhang, and J. Yang, "System dynamics model based on evolutionary game theory for quality supervision among construction stakeholders," Journal of Civil Engineering and Management, vol. 24, no. 4, pp. 318-330, 2018.

[32] L. Cai, W. Cai, Z. Xiong, S. Chen, and Z. Yu, "Research on multi-players evolutionary game of environmental pollution in system dynamics model," Journal of Computational and Theoretical Nanoscience, vol. 13, no. 3, pp. 1979-1984, 2016. 
[33] X. G. Zhao and Y. Z. Zhang, "The system dynamics (SD) analysis of the government and power producers' evolutionary game strategies based on carbon trading (CT) mechanism: a case of China," Sustainability, vol. 10, no. 4 , p. 1150, 2018.

[34] P. D. Taylor and L. B. Jonker, "Evolutionary stable strategies and game dynamics," Mathematical Biosciences, vol. 40, no. 12, pp. 145-156, 1978. 